Analyse: Ber. für $\mathrm{C}(\mathrm{OH})\left(\mathrm{SO}_{3} \mathrm{~K}\right)_{3}, \mathrm{H}_{2} \mathrm{O}$

Procente: C 3.0, $\quad \mathrm{H}$ 0.8, $\quad \mathrm{K} 29.0, \mathrm{~S} 23.8, \quad \mathrm{H}_{2} \mathrm{O}$ 4.5.

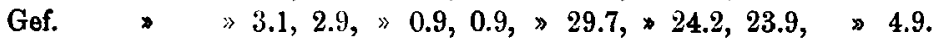

Das Salz bildet harte, stark glänzende Nadeln und zeigte in jeder Beziehung das Verhalten der zuerst von Albrecht ${ }^{1}$ ) beschriebenen Verbindung, wie wir uns durch einen directen Vergleich mit einem von Hrn. Prof. Rathke gütigst zur Verfügung gestellten Präparat überzeugen konnten.

Baryumsalz. Dieses charakteristische Salz wird aus der Lösung des Kaliumsalzes durch Chlorbaryum in glänzenden Krystallblättchen gefälit.

Analyse: Ber. für $\mathrm{C}(\mathrm{OH})\left(\mathrm{SO}_{3} \mathrm{ba}\right)_{3}, 4 \mathrm{H}_{2} \mathrm{O}$.

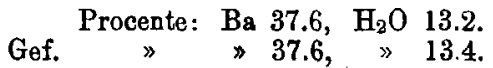

Bei der Untersuchung der oben beschriebenen jodhaltigen Verbindungen sind wir von Hrn. Dr. Franz Coblitz auf's Wirksamste unterstützt worden, wofür wir demselben auch an dieser Stelle unsern besten Dank aussprechen.

472. H. v. Pechmann und L. Vanino: Ueber die Finwirkung von Benzoylchlorid auf Urethan.

[Notiz aus dem Laborat. der k. Akademie der Wissenschaften zu München.] (Eingeg. am 1. October: mitgetheilt in der Sitzung ron Hrn. A. Reissert.)

Durch äussere Umstände von der weiteren Bearbeitung obigen Themas abgehalten, theilen wir unsere bisherigen Erfahrungen darüber in Kürze mit.

Um eventuell zu einem Benzenylphenylamidin von bestimmter Structur za gelangen, beabsichtigten wir vom Benzoylurethan auszugehen. Nach den in der Literatur ${ }^{2}$ ) vorliegenden Angaben scheint eine bequeme Darstellungsmethode des Körpers nicht bekannt zu sein. Wir glauben deshalb nachstehendes Verfahren nittheilen zu dürfea, welches, zwar noch nicht ausgearbeitet und weit entfernt befriedigend zu sein, immerhin beliebige Quantitäten der Verbindung zugänglich macht. Als Nebenproduct erhalten wir wechselnde Mengen Benzoylallophansă ureester, manchmal auch einen noch nicht identificirten Körper vom Schmp. $201^{\circ}$.

\title{
Benzoylurethan, $\mathrm{C}_{6} \mathrm{H}_{5} \mathrm{CONHCOOC}_{2} \mathrm{H}_{5}$.
}

Aequimolekulare Mengen Urethan, Benzoylchlorid und Pyridin werden 10-12 Stunden in kochendem Wasserbad erbitzt. Die dann

1) Ann. d. Chem. 161, 139.

3).Lössner, Journ. f. prakt. Chem. [2] 10, 254. Hantzsch, diese Berichte 26, 928 . 
halb erstarrte Masse wird in einem geräumigen Scheidetrichter mit überschüssiger Natronlauge und Aether geschüttelt, bis fast alles Feste verschwunden ist. Aus der alkalischen Flüssigkeit fällt beim Ansäuern ein nach kurzer Zeit erstarrender Körper aus, welcher in kochendem Alkohol aufgelöst wird. Beim Abkühlen krystallisirt zuerst fast reiner Benzoylallophansäureester aus, während sich aus der Mutterlauge, wenn sie warm mit Wasser bis zur Trübung versetzt wird, Benzoyluretban als allmählich zu derben Säulen erstarrendes Oel abscheidet. Ausbeute schwankend, im günstigsten Fall bisher 50 pCt. vom angewandten Urethan.

Analyse: Ber. für $\mathrm{C}_{10} \mathrm{H}_{11} \mathrm{NO}_{3}$.

Procente: C 62.2, H 5.7, N 7.3.

$$
\text { Gef. " " } 62.5, \text { " } 5.9, \text {, 7.7, 7.6. }
$$

Farblose Nadeln oder Säulen aus verdünntem Alkohol. Schmp. 110 ${ }^{\circ}$. Sehr leicht löslich in Alkohol und Aether, schwer in Wasser, löslich in Alkalien. Beim Erhitzen für sich zerfällt das Uretban zum Theil in Benzonitril, Kohlendioxyd und Alkohol.

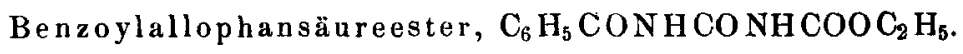

Bildung siehe oben. Seidenglänzende verfilzte Nadeln aus Alkobol. Analyse: Ber. für $\mathrm{C}_{11} \mathrm{H}_{12} \mathrm{~N}_{2} \mathrm{O}_{4}$.

$$
\begin{aligned}
& \text { Procente: C 55.9, H } 5.1, \quad \text { N } 11.9 \\
& \text { Gef. } \quad \text { \55.9, 55.9, 》5.3, 5.2, 》 } 12.1 \text {. }
\end{aligned}
$$

Nach wiederholtem Umkrystallisiren steigt der Schmelzpunkt anf $179^{\circ}$. Schwer löslich in Alkohol, leichter in den meisten sonstigen Solventien. Erhitzt man die Verbindung über ihren Schmelzpunkt, so wird sie bei $200-205^{\circ}$ wieder fest, während gleichzeitig Benzonitril abdestillirt; der feste Körper krystallisirt aus Alkohol in glänzenden Blättehen vom Schmp. 2230. Gegen Alkalien verbält sich der Allophanester wie eine schwache Säure. Diese Eigenschaft spricht für die oben angeführte symmetrische Formel und macht die ebenfalls mögliche unsymmetrische Formel $\mathrm{NH}_{2} \mathrm{CON}<\underset{\mathrm{COOCO}_{2} \mathrm{H}_{5}}{\mathrm{COC}_{6} \mathrm{H}_{3}}$ weniger wahrscheinlich.

Auch Kretzschmar ${ }^{1}$ ), welcher den Körper durch Erhitzen von Benzoylchlorid mit Urethan auf $150-160^{\circ}$ dargestellt hat, bevorzugt ohne Gründe dafür anzugeben - die symmetrische Formel. Den Schmelzpunkt findet er zwar als bei etwa $163^{\circ}$ « liegend; er hatte jedoch zweifellos die nämliche Substanz wie wir in Händen, da ein von uns nach seinem Verfahren dargestelltes Präparat nach wiederholtem Unkrystallisiren ebenfalls bei $179^{\circ}$ schmolz.

1) Diese Berichte 8, 104. 